\title{
SOROPREVALÊNCIA DE Toxoplasma gondii EM GATOS DOMICILIADOS EM PALOTINA, PARANÁ, BRASIL
}

\author{
Laura Zanella Souza \\ Raquel Granato Alves Rodrigues ${ }^{2}$ \\ Devielle Aline Dahmer de Oliveira ${ }^{3}$ \\ Juliane Laís Roman ${ }^{4}$ \\ Marivone Valentim Zabott $^{5}$ \\ Simone Benghi Pinto ${ }^{6}$ \\ Laura Helena França de Barros Bittencourt ${ }^{7}$ \\ Mônica Kanashiro Oyafuso ${ }^{8}$
}

SOUZA, L. Z.; RODRIGUES, R. G. A.; OLIVEIRA, D. A. D.; ROMAN, J. L.; VALENTIM-ZABOTT, M.; PINTO, S. B.; BITTENCOURT, L. H. F. B.; OYAFUSO, M. K. Soroprevalência de Toxoplasma gondii em gatos domiciliados em Palotina, Paraná, Brasil. Arq. Ciênc. Vet. Zool. UNIPAR, Umuarama, v. 20, n. 3, p. 123-126, jul./set. 2017.

RESUMO: A toxoplasmose é uma zoonose causada pelo protozoário Toxoplasma gondii, sendo uma das parasitoses mais difundidas mundialmente. O presente estudo teve como objetivo analisar a prevalência de anticorpos IgG anti-T. gondii em gatos atendidos no Hospital Veterinário da UFPR e em clínicas veterinárias do município de Palotina. Foram analisadas 100 amostras de soro sanguíneo, por meio da reação de imunofluorescência indireta (RIFI) e juntamente foi feito um levantamento epidemiológico por meio de questionário, respondido pelos proprietários dos animais, com relação as condições de vida dos felinos, com a finalidade de caracterizar fatores associados ao risco de infecção por $T$. gondii nos animais estudados. As informações obtidas foram analisadas pelo programa Epi Info 3,05. A prevalência de anticorpos IgG anti- $T$. gondii para a população analisada foi de 29\% (29/100). Dentre as variáveis estudadas, o acesso à rua, a outras casas, ao telhado, a presença de pombos na residência, o hábito de caçar, o fato de comer restos de comida e a idade (acima de um ano), foram associadas significativamente com a presença da infecção pelo protozoário. As informações obtidas são relevantes para caracterizar fatores de risco e vias de transmissão da toxoplasmose nos animais estudados e elaborar estratégias para o controle e profilaxia da doença entre os felinos domésticos da região.

PALAVRAS-CHAVE: Prevalência. Toxoplasmose. Gatos domésticos.

\section{Toxoplasma gondii SEROPREVALENCE IN CATS IN THE CITY OF PALOTINA, PARANÁ, BRAZIL}

ABSTRACT: Toxoplasmosis is a zoonosis caused by the Toxoplasma gondii protozoan, being one of the most widespread parasitosis in the world. This study aimed at analyzing the prevalence of anti-T.gondii IgG antibodies in cats treated at the Veterinary Hospital from the Federal Univeristy of Paraná and at private veterinary clinics in the city of Palotina. A hundred serum samples were analyzed using indirect immunofluorescence reaction (IIF). An epidemiological survey was developed through a questionnaire answered by the animal owners regarding the life conditions of the animals with the purpose of characterizing factors associated with the risk of $T$. gondii infection in the studied animals. The information obtained was analyzed using the Epi Info 3.05 program. The prevalence found for anti-T.gondii IgG antibodies in the analyzed population was $29 \%$ (29/100). Among the studied variables, access to the street, to other houses, to the roof, presence of pigeons in the residence, hunting habit, eating leftovers and age (older than one) were significantly associated with the presence of the protozoan. The information obtained is relevant to characterize toxoplasmosis risk factors and transmission routes in the studied animals and to develop strategies for the control and prophylaxis of the disease among domestic cats in the region.

KEYWORDS: Domestic cats. Prevalence. Toxoplasmosis.

\section{SOROPREVALENCIA DE Toxoplasma gondii EN GATOS DOMICILIADOS EN PALOTINA, PARANÁ, BRASIL}

RESUMEN: La toxoplasmosis es una zoonosis causada por el protozoario Toxoplasma gondii, siendo una de las parasitosis más difundidas mundialmente. El presente estudio tuvo como objetivo analizar la prevalencia de anticuerpos IgG anti-T.

DOI: 10.25110 /arqvet.v20i3.2017.6395

${ }^{1}$ Acadêmica do curso de Medicina Veterinária, Universidade Federal do Paraná - Setor Palotina. laurazanellasouza@gmail.com

${ }^{2}$ Médica Veterinária. raquelgranatto@gmail.com

${ }^{3}$ Médica Veterinária. vetcampo1@gmail.com

${ }^{4}$ Médica Veterinária. juliane_roman@hotmail.com

${ }^{5}$ Médica Veterinária. Doutora em Zootecnia (UEM). Docente do Departamento de Biociências da Universidade Federal do Paraná- Setor Palotina. marvalentim@ufpr.br

${ }^{6}$ Bióloga. Doutora em Ciências Biológicas (UFPR). Docente do Departamento de Biociências da Universidade Federal do Paraná - Setor Palotina. sbenghi@ yahoo.com.br

${ }^{7}$ Médica Veterinária, Doutora em Ciência Animal (UEL). Docente do Centro Universitário da Fundação Assis Gurgacz. laura.h.f.b@hotmail.com

${ }^{8}$ Médica Veterinária, Mestre em Clínica Veterinária (UEL). Docente do Departamento de Ciências Veterinárias da Universidade Federal do Paraná- Setor

Palotina. mokanashiro@ufpr.br 
gondii en gatos atendidos en el Hospital Veterinario de la UFPR y en clínicas veterinarias del municipio de Palotina. Se analizaron 100 muestras de suero sanguíneo, a través de la reacción de Inmunofluorescencia indirecta (RIFI) y juntamente se hizo un levantamiento epidemiológico a través de cuestionario, contestado por los propietarios de los animales, con relación a las condiciones de vida de los felinos, con la finalidad de caracterizar factores asociados al riesgo de infección por T.gondii en los animales estudiados. Las informaciones obtenidas fueron analizadas por el programa Epi Info 3,05. La prevalencia de anticuerpos IgG anti-T.gondii para la población analizada fue del 29\% (29/100). Entre las variables estudiadas, el acceso a la calle, a otras casas, al tejado, la presencia de palomas en la residencia, el hábito de cazar, el hecho de comer restos de comida y la edad (por encima de un año), se asociaron significativamente con la presencia de la infección por el protozoario. Las informaciones obtenidas son relevantes para caracterizar factores de riesgo y vías de transmisión de la toxoplasmosis en los animales estudiados y elaborar estrategias para el control y profilaxis de la enfermedad entre los felinos domésticos de la región. PALABRAS CLAVE: Gatos domésticos. Prevalencia. Toxoplasmosis.

\section{Introdução}

A toxoplasmose é uma zoonose causada pelo protozoário Toxoplasma gondii. Os felinos domésticos e selvagens são seus hospedeiros definitivos e animais homeotérmicos, os hospedeiros intermediários. A infecção pode ocorrer pela ingestão dos oocistos, que são eliminados nas fezes de felídeos, pelos cistos presentes em tecidos de hospedeiros intermediários e pela via transplacentária (TENTER, 1998).

Essa doença em humanos representa importância no surgimento de alterações neonatais como lesões oculares, hidrocefalia, microcefalia, calcificações cerebrais, deficiência intelectual e alterações psicomotoras (FRENKEL, 1973; AMATO et al., 1982). De acordo com Galvan Ramirez et al. (1999) citado Hill e Dubey (2002) estima-se que 1/3 da população humana mundial possua anticorpos para o $T$. gondii, sendo que o Brasil apresenta índices elevados de prevalência. Essa taxa aumenta com a idade do indivíduo, devido à oportunidade maior de adquirir a infecção.

O diagnóstico clínico da toxoplasmose tanto em humanos como em animais é muito difícil de ser estabelecido, por isso é necessário o diagnóstico laboratorial para confirmação. Dentre os métodos para diagnóstico laboratorial estão os exames parasitológicos e os imunológicos. Os testes parasitológicos apresentam muitas dificuldades e limitações, por isso os métodos sorológicos são os mais utilizados. Os testes sorológicos consistem na pesquisa de anticorpos das classes IgM e IgG, que podem ser detectados pelo ensaio imunoadsorvente ligado à enzima (ELISA), reação de imunofluorescência indireta (RIFI), hemaglutinação indireta (HAI), reação de fixação de complemento e a reação de Sabin-Feldman (REY, 2001; MACRE, 2002).

Vários artigos trazem dados sobre a soroprevalência e a epidemiologia de $T$. gondii em gatos domiciliados em diferentes regiões do país, entretanto, poucos tratam de informações sobre o assunto em gatos domiciliados na região oeste do Paraná e especificamente no município de Palotina. Diante de tal panorama, o presente estudo teve como objetivo avaliar a soroprevalência de $T$. gondii, em gatos atendidos no Hospital Veterinário do Setor Palotina da UFPR e clínicas veterinárias do município e contribuir com informações a respeito da epidemiologia da toxoplasmose nessa população. pelo Hospital Veterinário UFPR e as demais pelas clínicas veterinárias particulares do município. No momento da coleta foi aplicado um questionário epidemiológico, ao proprietário do animal, contendo questões relativas à idade, sexo, alimentação e ambiente em que o animal vive, com intuito de avaliar as possíveis associações com a soropositividade para toxoplasmose. A todos os proprietários foram solicitados a assinar o Termo de Consentimento Livre e Esclarecido (TCLE) e o protocolo da pesquisa foi aprovado pela Comissão de Ética no Uso de Animais (CEUA/UFPR), parecer $n^{\circ}$ 39/2013, aprovado em 20/12/2013.

As amostras de sangue foram enviadas ao Laboratório de Parasitologia e Imunologia da Universidade Federal do Paraná - Setor Palotina. Estas foram processadas para obtenção do soro e submetidas à reação de imunofluorescência indireta para detecção de anticorpos da classe IgG anti- $T$. gondii, por meio do teste comercial Imunodot ${ }^{\circledR}$. O microscópio de imunofluorescência utilizado para visualização dos taquizoítos foi o modelo Olympus FSX 100.

Todas as informações obtidas nos questionários epidemiológicos foram analisadas pelo programa Epi Info 3.5 (CDC, Atlanta, USA) e associadas com os resultados obtidos nos exames sorológicos, utilizando o teste do Qui-Quadrado $\left(\mathrm{x}^{2}\right)$, adotando-se $95 \%$ de intervalo de confiança com $\alpha=5 \%$, para assim verificação de possíveis associações.

\section{Resultados}

A prevalência de anticorpos IgG anti-T. gondii foi de $29 \%$. As amostras foram consideradas positivas quando mais de $50 \%$ dos taquizoítos de cada campo apresentaram fluorescência periférica completa.

As variáveis epidemiológicas significativas foram: acesso à rua, à outras casas, ao telhado, à presença de pombos na residência, ao hábito de caçar, ao fato de comer restos de comida e à idade (Tabela 1).

$\mathrm{Na}$ análise epidemiológica de algumas variáveis ao invés do qui-quadrado de Yates foi considerado o exato do Fisher devido ao número de positivos e negativos em relação ao fator de exposição.

\section{Materiais e Métodos}

No período de março a maio de 2015 foram coletadas 100 amostras de sangue de felinos domésticos, domiciliados no município de Palotina - PR, 51 machos e 49 fêmeas. Do total de amostras obtidas, 72 foram fornecidas 
Tabela 1: Variáveis significativas para presença de anticorpos IgG anti-Toxoplasma gondii e seus respectivos valores epidemiológicos obtidos, pelo programa Epi Info 3.5 em gatos domiciliados no município de Palotina, Paraná, Brasil.

\begin{tabular}{l|c|c}
\multicolumn{1}{c|}{ VARIÁVEL } & VALOR DE 'p' & Odds Ratio (IC 95\%) \\
\hline Acesso ao telhado & 0,0020 (Yates) & $4,82(1,82-12,79)$ \\
\hline Caça & 0,0011 (Fisher) & $6,50(1,79-23-50)$ \\
\hline Alimenta-se com resto de comida & 0,0239 (Fisher) & $11,20(1,19-105,03)$ \\
\hline Faixa etária (acima de um ano) & 0,0042 (Yates) & $3,61(1,37-9,54)$ \\
\hline Pombos na casa & 0,0139 (Yates) & $3,83(1,39-10,55)$ \\
\hline Acesso à rua & 0,0134 (Yates) & $4,03(1,56-10,35)$ \\
\hline Acesso à outras casas & 0,0055 (Yates) & .
\end{tabular}

O valor de "p" significativo $<0,05$. (IC) Intervalo de Confiança. ** Não há valor de Odds Ratio (tabela 3x2).

\section{Discussão}

Andrade et al. (2015) coletaram 171 amostras de sangue de felinos atendidos em clínicas veterinárias de Cascavel, no Paraná. As amostras foram analisadas pela Reação de Imunofluorescência Indireta para a detecção de anticorpos anti-T.gondii, revelando uma soroprevalência de $28,07 \%$ (48/171), a qual é semelhante a encontrada nesse estudo. Assim como no presente trabalho foi aplicado um questionário epidemiológico aos proprietários e entre as variáveis significativas estão a presença de pombos e pardais e o acesso ao pátio ou quintal, estes corroboram com os achados dessa pesquisa.

Prevalência inferior a encontrada neste estudo foi relatada por Schnell (2012), que realizou uma pesquisa sorológica para determinar a prevalência de anticorpos anti- $T$. gondii em amostras de soro provenientes de 90 felinos domésticos atendidos no Hospital de Clínicas Veterinárias da UFRGS, na cidade de Porto Alegre, RS. A pesquisa foi realizada utilizando a reação de hemaglutinação indireta. Dos 90 animais analisados, $15(16,7 \%)$ apresentaram-se positivos para anticorpos (titulação $>1: 64$ ).

Ao estudarem a prevalência de anticorpos anti- $T$. gondii em pessoas, que eram proprietários de gatos, na área metropolitana de Guadalajara, Jalisco, Ramírez et al. (1999) verificaram que $64,4 \%$ foram soropositivos. O grupo dos felinos apresentou prevalência de 8,3\% de $\operatorname{IgM}, 62,5 \%$ de IgA e 70,8\% de IgG anti-Toxoplasma, valor este superior ao encontrado no presente estudo. A análise dos dados revelou que humanos que vivem com felinos infectados por $T$. gondii teriam predisposição a infectar-se.

Marana et al. (1994) estudaram os aspectos epidemiológicos e sorológicos da toxoplasmose em 334 bovinos abatidos em Londrina, Paraná. As amostras, assim como no presente trabalho, foram submetidas à imunofluorescência indireta. Obtiveram 32,34\% de soropositivos. Sendo: Norte do Paraná 50,77\%, Norte Novo do Paraná 32,50\%, Oeste do Paraná 17,78\%, Centro do Paraná 15,38\%, Sul do Mato Grosso do Sul 30,77\% (titulação > ou = a 1:64). A prevalência sendo relativamente significativa na região do Paraná é algo preocupante, pois no presente estudo observamos que alguns proprietários alimentam seus gatos com carnes cruas e restos de comida, sendo a última uma variável significativa.

Ao realizarem um estudo sobre a soroprevalência de anticorpos IgG anti-T. gondii em 408 suínos, utilizando a reação de imunofluorescência indireta, Millar et al. (2008), avaliaram animais de 25 municípios da região Sudoeste do
Estado do Paraná. Dos 408 animais, 25,5\% foram positivos (titulação $\geq$ a1:64). Os dados demonstram a necessidade de maior atenção no consumo de carnes cruas ou mal passadas e sua utilização na alimentação dos gatos.

Daguer et al. (2004) avaliaram amostras de soro de 348 bovinos e de 64 funcionários em quatro matadouros de Pato Branco, no Paraná. As amostras de bovinos foram submetidas à reação de imunofluorescência indireta. E apresentaram soropositividade (IgG) de 41,4\%. Os soros humanos foram submetidos aos testes de RIFI e de ELISA (IgG) e apresentaram soropositividade $67,2 \%$ e $84,4 \%$ respectivamente. Porém, variáveis de idade, sexo, tempo de serviço no abatedouro, contato com gatos e hábito de ingerir carne crua ou mal cozida não se apresentaram significativas.

Pinto et al. (2009), coletaram amostras sorológicas de 245 gatos em Porto Alegre - RS e, diferentemente do presente estudo, além da RIFI, foi realizada a hemaglutinação indireta. Um questionário epidemiológico foi aplicado, e avaliados os dados. foi constatado estatisticamente que os animais que tinham acesso à rua e os animais mais velhos eram mais afetados, corroborando com os achados da presente pesquisa. Já as demais variáveis como sexo, raça e tipo de alimentação não influenciaram os resultados, diferente desse estudo em que a alimentação com restos de comida e o hábito de caçar foi significativo.

Associações semelhantes são esperadas já que o solo contaminado pelos oocistos do parasito é fonte de contaminação constante, e o acesso dos felinos às áreas onde possam caçar faz que estejam mais expostos à contaminação. Gatos adultos apresentam maior positividade devido à maior probabilidade de terem tido contato com o agente. O mesmo foi observado em outras espécies, como nos cães (MOURA et al., 2009) e ovinos (SOCCOL et al., 2009).

\section{Conclusão}

Os resultados obtidos no presente estudo demonstram uma prevalência significativa de anticorpos IgG anti- $T$. gondii nos gatos atendidos em clínicas veterinárias de Palotina e no Hospital Veterinário da UFPR. Com base nos dados levantados, foi possível verificar alguns fatores associados a positividade para toxoplasmose, podendo-se concluir que na população estudada certas ações como: fornecer resto de comida, permitir acesso às ruas e telhados, possibilitam a infecção destes. Verifica-se, portanto, a importância da toxoplasmose no município de Palotina, devido à prevalência nos animais estudados e à necessidade de conscientização dos 
proprietários, sobre os métodos profiláticos para auxiliar no controle desta importante zoonose.

\section{Agradecimentos}

Aos médicos veterinários Joyce Alves, Filipe Krasinski Cestari e Priscila Pereira pela contribuição na pesquisa.

\section{Referências}

AMATO NETO, V. et al. Toxoplasmose. São Paulo: Sarvier, 1982. $155 \mathrm{p}$.

ANDRADE, A. C. de S. et al. Prevalência de anticorpos anti-Toxoplasma gondii em felinos frequentadores de clínicas e hospitais veterinários de Cascavel, Paraná, Brasil. Arquivos de Ciência Veterinária e Zoologia da UNIPAR, v. 18, n. 4, p. 221-224, out./dez. 2015.

DAGUER, H. et al. Soroprevalência de anticorpos anti-Toxoplasma gondii em bovinos e funcionários de matadouros da microrregião de Pato Branco, Paraná, Brasil. Ciência Rural, v. 34, n. 4, p. 1133-1137, 2004.

FRENKEL, J. K. et al. Toxoplasma in and around US. Bioscience, v. 23, n. 6, p. 343-352, 1973.

EPI INFO. Epidemiology of program office. Disponível em: <http://www.cdc.gov/epiinfo/index.html $>$. Acesso em: 11 fev. 2015

MACRE, M. S. Avaliação da quantificação da avidez dos anticorpos maternos na abordagem laboratorial da toxoplasmose congênita. São Paulo, 2002. 121 f. Dissertação (Mestrado em Biologia da Relação Patógeno-Hospedeiro) - Instituto de Ciências Biomédicas, Universidade de São Paulo, São Paulo, 2002.

MARANA, E. R. M. et al. Ocorrência de anticorpos antiToxoplasma gondii em bovinos de corte, abatidos em matadouros do Norte do Estado do Paraná - Brasil. Semina: Ciências Agrárias, v. 15, n. 1, p. 38-40, 1994.

MILLAR, P. R. et al. Toxoplasma gondii: estudo soroepidemiológico de suínos da região Sudoeste do Estado do Paraná. Pesquisa Veterinária Brasileira, v. 28, n. 1, p. 15-18, 2008.

MOURA, A. B. et al. Ocorrência de anticorpos e fatores de risco para infecção por Toxoplasma gondii em cães, nas cidades de Lages e Balneário Camboriú, Santa Catarina, Brasil. Revista Brasileira de Parasitologia Veterinária, v. 18, n. 3, p. 52-56, 2009.

PINTO, L. D. et al. Soroepidemiologia de Toxoplasma gondii em gatos domiciliados atendidos em clínicas particulares de Porto Alegre, RS, Brasil. Ciência Rural, v. 39, n. 8, p. 2464-2469, 2009.

RAMÍREZ, M. L. G. et al. Presence of anti-Toxoplasma antibodies in humans and their cats in the urban zone of Guadalajara. Revista da Sociedade Braileira de Medicina Tropical, v. 32, n. 5, p. 483-488, 1999.

REY, L. Toxoplasma gondii e Toxoplasmose. In: REY, L. Rey parasitologia. 3. ed. Rio de Janeiro: Guanabara Koogan, 2001. p. 321-333.

SCHNELL, M. Toxoplasmose felina - Revisão de literatura e soroprevalência de Toxoplasma gondii em felinos domésticos atendidos no Hospital de Clínicas Veterinárias da UFRGS. 2012. Monografia (Bacharelado em Medicina Veterinária) - Universidade Federal do Rio Grande do Sul, Porto Alegre, 2012.

SOCCOL, V. T. et al. Ocorrência de anticorpos antiToxoplasma gondii em ovinos das áreas urbanas e periurbanas de Curitiba, Paraná. Revista Brasileira Parasitologia Veterinária, v. 18, supl. 1, p. 69-70, dez. 2009.

TENTER, A. M. Current knowledge on the epidemiology of infections with Toxoplasma. The Tokai Journal of Experimental and Clinical Medicine, v. 23, p. 391, 1998.

Recebido em: 23.10.2017 Aceito em: 23.12.2017 